\title{
CELL-CELL INTERACTIONS OF ISOLATED AND CULTURED OLIGODENDROCYTES: FORMATION OF LINEAR OCCLUDING JUNCTIONS AND EXPRESSION OF PECULIAR INTRAMEMBRANE PARTICLES $^{1}$
}

\author{
PAUL T. MASSA, ${ }^{* 2}$ SARA SZUCHET, $\$$ AND ENRICO MUGNAINI ${ }^{*, 3}$ \\ ${ }^{*}$ Department of Biobehavioral Sciences, The University of Connecticut, Storrs, Connecticut 06268 and $\ddagger$ Department of \\ Neurology, The University of Chicago, Chicago, Illinois 60637
}

Received March 29, 1984; Accepted June 26, 1984

\begin{abstract}
Oligodendrocytes were isolated from lamb brain. Freshly isolated cells and cultured cells, either 1- to 4-dayold unattached or 1- to 5-week-old attached, were examined by thin section and freeze-fracture electron microscopy. Freeze-fracture of freshly isolated oligodendrocytes showed globular and elongated intramembrane particles similar to those previously described in oligodendrocytes in situ. Enrichment of these particles was seen at sites of inter-oligodendrocyte contact. Numerous gap junctions and scattered linear tight junctional arrays were apparent. Gap junctions were connected to blebs of astrocytic plasma membrane sheared off during isolation, whereas tight junctions were facing extracellular space or blebs of oligodendrocytic plasma membrane. Thin sections of cultured, unattached oligodendrocytes showed rounded cell bodies touching one another at points without forming specialized cell junctions. Cells plated on polylysine-coated aclar dishes attached, emanated numerous, pleomorphic processes, and expressed galactocerebroside and myelin basic protein, characteristic markers for oligodendrocytes. Thin sections showed typical oligodendrocyte ultrastructure but also intermediate filaments not present in unattached cultures. Freeze-fracture showed intramembrane particles similar to but more numerous, and with a different fracture face repartition, than those seen in oligodendrocytes, freshly isolated or in situ. Gap junctions were small and rare. Apposed oligodendrocyte plasma membrane formed linear tight junctions which became more numerous with time in culture. Thus, cultured oligodendrocytes isolated from ovine brains develop and maintain features characteristic of mature oligodendrocytes in situ and can be used to explore formation and maintenance of tight junctions and possibly other classes of cellcell interactions important in the process of myelination.
\end{abstract}

Neuronal-glial interaction in the CNS involve two main classes of glial cells: the oligodendrocytes, which provide the myelin sheaths surrounding axons, and the astrocytes, which ensheath nerve cell bodies, dendrites, boutons, and unmyelinated axons, and delimit the neural tissue from pial and vascular surfaces (Peters et al., 1976). Glial-glial interactions also occur (reviewed by Mugnaini, 1982, and Orkand, 1982); for example, astrocytes have been shown to be coupled to one another by gap junctions (Brightman and Reese, 1969; Dermietzel, 1974; Peters et al., 1976; Tani et., 1977; Friedrich et al., 1980; Sandri et al., 1982).

Recently, Massa and Mugnaini (1982) re-examined the junc-

\footnotetext{
${ }^{1}$ We are grateful to Drs. B. Ranscht and K. Stefansson, respectively, for a gift of a monoclonal antibody against galactocerebroside and for the immunofluorescence staining. We thank Messrs. Paul E. Polak and Charles Coffey for excellent technical assistance. This work was supported by United States Public Health Service Grant 09904 (E. M.) and National Multiple Sclerosis Society Grant RG 1223-B3 (S. S.).

${ }^{2}$ Present address: Institut für Virologie und Immunobiologie, Universität Würzburg, Versbacher Strasse 7, 8700 Würzburg, West Germany.

${ }^{3}$ To whom reprint requests should be addressed.
}

tional appositions between different types of glia using the freeze-fracture method and concluded that oligodendrocytes make tight junctional contacts with other oligodendrocytes, but they interact via gap junctions with astrocytes. Their assertions stem from having been able to discriminate between oligodendrocytic and astrocytic plasma membranes by virtue of their distinct intramembrane particles and to identify aggregates of gap junctional particles joining these membranes. Astrocytes were identified by their orthogonal intramembrane particle arrays (Dermietzel, 1974; Landis and Reese, 1974; Anders and Brightman, 1979, 1981; Cullen and Gulley, 1980; Hatton and Ellisman, 1981; Sandri et al., 1982), whereas oligodendrocytes were identified by peculiar elongated particles (Massa and Mugnaini, 1982).

Glial cell properties can be studied not only in situ, but also in culture. Development of procedures for the isolation and long-term culture of mature oligodendrocytes (Szuchet et al., 1980a; Gebiecke-Harter et al., 1981; Lisak et al., 1981) and the possibility of having cultures from immature brains where the two classes of macroglial cells are mixed or isolated from one another (McCarthy and DeVellis, 1980) permit the addressing of questions concerning cell-cell interaction that were not conceivable before. We have recently succeeded in separating and 
culturing over extended periods of time a homogeneous population of cells from lamb brain that possess the biochemical and morphological characteristics of oligodendrocytes: they have round and small cell bodies, extend long and thin processes, express specific markers such as galactocerebroside, myelin basic protein, and $2^{\prime}, 3^{\prime}$-cyclic nucleotide phosphodiesterase (Szuchet et al., 1980b; Yim and Szuchet, 1981; Szuchet and Yim, 1984), and incorporate high levels of ${ }^{35} \mathrm{SO}_{4}{ }^{2-}$ into sulfatide (Mack and Szuchet, 1980; Szuchet et al., 1983). These cells show a remarkable tendency to form close contact with each other, suggestive of cell-to-cell interaction (Wollman et al., 1981). Improvements in the preparation procedure yield cultures that are nearly homogeneous and make it possible to reproducibly study the ability of purified oligodendrocytes to form membrane specializations at sites of contact with one another in the absence of neurons and astrocytes. In this study we investigate the nature of inter-oligodendrocyte junctional complexes, as well as the microarchitecture of oligodendroglial plasma membrane using thin section and freeze-fracture electron microscopy. Some of the results have been presented elsewhere in preliminary form (Massa et al., 1983).

\section{Materials and Methods}

Preparation of oligodendrocytes. Oligodendrocytes were isolated from 4- to 6-month-old lamb brains by a modification of a previously published procedure (Szuchet et al., 1980a; Szuchet and Stefansson, 1980). We followed the old method up to the point where a crude cell pellet $\left(\mathrm{P}_{1}\right)$ is obtained after enzymatic and mechanical tissue disruption in the presence of EDTA. The pellet was then processed as follows: $P_{1}$ was resuspended in Hanks' balanced salt solution ( $\mathrm{Ca}^{2+}$ and $\mathrm{Mg}^{2 '}$ ' free) at half strength, $0.9 \mathrm{M}$ sucrose was added, and then the pellet was applied on a linear gradient made of $1.0 \mathrm{M}$ to $1.15 \mathrm{M}$ sucrose $+4 \%$ Dextran 70 and centrifuged at $1020 \times g$ for $10 \mathrm{~min}$. Three bands separated on this gradient (Szuchet et al., 1980a). We collected only cells from band III (B3), which were slowly diluted with Hanks' solution to twice the original volume, centrifuged, and washed once. Cells were then suspended in culture medium (Dulbecco's modified Eagle's medium supplemented with $20 \%$ horse serum and $2 \mathrm{~mm}$ glutamine), plated on Falcon culture Petri dishes at a concentration of $2 \times 10^{6}$ cells $/ \mathrm{ml}$, and kept at $37^{\circ} \mathrm{C}$ in an atmosphere of $95 \%$ air and $5 \% \mathrm{CO}_{2}$ at $90 \%$ humidity. Approximately $60 \%$ of the cells did not attach to the culture dishes but formed floating $(f)$ aggregates or clusters. We refer to these cells as B3f. After 3 to 4 days in vitro, the supernatant containing the floating clusters was removed and centrifuged at low speed $(63 \times g)$ in a bench centrifuge for $5 \mathrm{~min}$. The $B 3 f$ cell pellet was resuspended in the above-mentioned culture medium and replated on polylysine-coated aclar plastic dishes (Allied Chemical Corp., Pottsville, PA) where they attached within $24 \mathrm{hr}$. We refer to the attached cells as B3fa. Cultures were fed every day with the same medium.

Thin section electron microscopy. Cells for thin section electron microscopy (B3f and B3fa) were processed as follows: fixation for $1 \mathrm{hr}$ with $2 \%$ glutaraldehyde in $0.12 \mathrm{M}$ sodium cacodylate huffer, $\mathrm{pH} 7.3$, at $37^{\circ} \mathrm{C}$; rinsing for $5 \mathrm{~min}$ with $0.12 \mathrm{M}$ cacodylate buffer; postfixation for $1 \mathrm{hr}$ with $2 \% \mathrm{OsO}_{4}$ in $0.12 \mathrm{M}$ cacodylate buffer at $4^{\circ} \mathrm{C}$; rinsing for 30 min with $0.05 \mathrm{M}$ maleate buffer, $\mathrm{pH} 5.2$, at $4^{\circ} \mathrm{C}$; en bloc staining for 30 min with $2 \%$ uranyl acetate in $0.05 \mathrm{M}$ maleate buffer, $\mathrm{pH} 5.2$, -at $4^{\circ} \mathrm{C}$; rinsing for $30 \mathrm{~min}$ in maleate buffer, $\mathrm{pH} 5.2$, at $4^{\circ} \mathrm{C}$; dehydration with a 1:1 mixlure of ethanol and ethylene glycol monomethyl ether; and embedding in LX 112 (Ladd Research Industries, Inc. Burlington, VT). Thin sections were stained with uranyl acetate and lead citrate and photographed on a Zeiss EM-10 electron microscope operated at 80 $\mathrm{kV}$.

Freeze-fracture electron microscopy. Cells for freeze-fracture (B3 and $B 3 f a$ ) were fixed with $1 \%$ formaldehyde and $0.5 \%$ glutaraldehyde in $0.12 \mathrm{M}$ cacodylate buffer for $15 \mathrm{~min}$ at $37^{\circ} \mathrm{C}$ and then at $4^{\circ} \mathrm{C}$ for 15 min. For cryoprotection, the fixed cells were infiltrated with 5-10-15$20-30 \%$ glycerol $(\mathrm{w} / \mathrm{v})$ in $0.12 \mathrm{M}$ cacodylate buffer at $4^{\circ} \mathrm{C}, \mathrm{pH} 7.2,15$ min each step, and then immersed in $30 \%$ glycerol in the buffer for 3 $\mathrm{hr}$. B3 cell pellets were freeze-fractured on a Balzers BMF-160 freezeetch apparatus (Balzers Union, Hudson, $\mathrm{NH}$ ) with a double replica device. B3fa cell cultures were freeze-fractured on a Denton DFE-3 freeze-etch apparatus (Denton Vacuum, Inc., Cherry IIill, NJ) by the method of Pauli et al. (1977). The replicas were processed as previously described (Massa and Mugnaini, 1982) and were photographed on a Zeiss EM-10 electron microscope operated at $80 \mathrm{kV}$. Plasmalemmal fracture faces were labeled according to the method of Branton et al. (1975).

Light microscopic immunocytochemistry. For immunocytochemical staining, live cells were incubated with a mouse monoclonal antibody against galactocerebroside (generously provided by Dr. B. Ranscht), followed by a fluorescein-conjugated goat anti-mouse IgG (N. L. Cappel Laboratories, Cochransville, PA), as specified elsewhere (Szuchet et al., 1980b). At the end of the procedure, cells were fixed with cold acid alcohol ( $5 \%$ glacial acetic acid in $95 \%$ alcohol) and examined with a Leitz epifluorescence microscope.

\section{Results}

Oligodendrocytes were analyzed under the three different conditions required for their isolation and long-term culture: (1) freshly isolated, pelleted $B 3$ oligodendrocytes were examined with freeze-fracture electron microscopy to ascertain the effects of the isolation procedure on the plasma membrane; (2) $B 3 f$ cells pelleted after 3 days of culture in conditions of nonattachment were studied with thin section electron microscopy to explore the cytoplasmic features before attachment; and (3) B3fa cultures ( 1 to 5 weeks old) were studied with light microscopic immunocytochemistry for ascertaining the expression of specific cell markers and with thin section and freezefracture electron microscopy to explore their ultrastructural features.

\section{Freeze-fracture electron microscopy of B3 oligodendrocytes}

Freeze-fracture $P$ faces of the plasma membranes of freshly isolated $B 3$ cells show intramembrane particles that are usually dispersed (Figs. 1 and 3 ) and only seldom arranged in patches (Fig. 2). In many cells one recognizes two types of intramembrane particles, globular and elongated, that are characteristic of oligodendrocytes in situ (Massa and Mugnaini, 1982). Ten electron micrographs of plasma membranes showing globular and elongated intramembrane particles were selected from cells that did not show particle patching; five micrographs included large vistas of the $P$ face and five included vistas of the $E$ face. Intramembrane particles were counted in a $10-\mu \mathrm{m}^{2}$ area in each micrograph. The average total density of particles is approximately $700 / \mu \mathrm{m}^{2}$ on the $\mathrm{P}$ face and $400 / \mu \mathrm{m}^{2}$ on the $\mathrm{E}$ face (Fig. 3). Globular and elongated particles occur in a nearly 1:1 ratio on both $\mathrm{P}$ and $\mathrm{E}$ faces. A similar particle repartition has been observed on plasmalemmal freeze-fracture faces of oligodendrocytes in situ (Massa and Mugnaini, 1982). Where two B3 oligodendrocytes come in close apposition, an enrichment of intramembrane particles occurs (Fig. 3, asterisks). Moreover, most of the $B 3$ oligodendrocytes show a varying number of special aggregates of 9-nm particles interpreted as noncrystalline gap junctions (Figs. 4 and 5). Linear tight junctional arrays are also apparent (Fig. 6). Overall, gap junctions occur more frequently than tight junctions, a feature also observed in oligodendrocytes in situ (Tani et al., 1977; Dermietzel et al., 1978; Massa and Mugnaini, 1982). Membrane-limited blebs adhere to the plasma membrane fracture faces in many of the isolated cells (inset $b$ in Fig. 4, and Figs. 5 and 6). Fragments of such blebs are often observed connected to gap junctions (insets $a$ and $b$ in Fig. 4, and Fig. 5). The freeze-fractured membranes of the blebs observed over the patches of gap junctional particles usually contain orthogonal assemblies of small particles, characteristic of astrocytic plasma membranes (Fig. 5, arrows). Tight junctions usually face intercellular ice (Fig. 7) and, at points, poorly defined membranous blebs (Fig. 6) on which elongated and globular particles can occasionally be recognized (not illustrated). Like those of oligodendrocytes in situ, the tight junctions of $B 3$ oligodendrocytes appear as interrupted strands and rows of particles on the $P$ face (Fig. 6) and as grooves with attached segments of strands or particles 

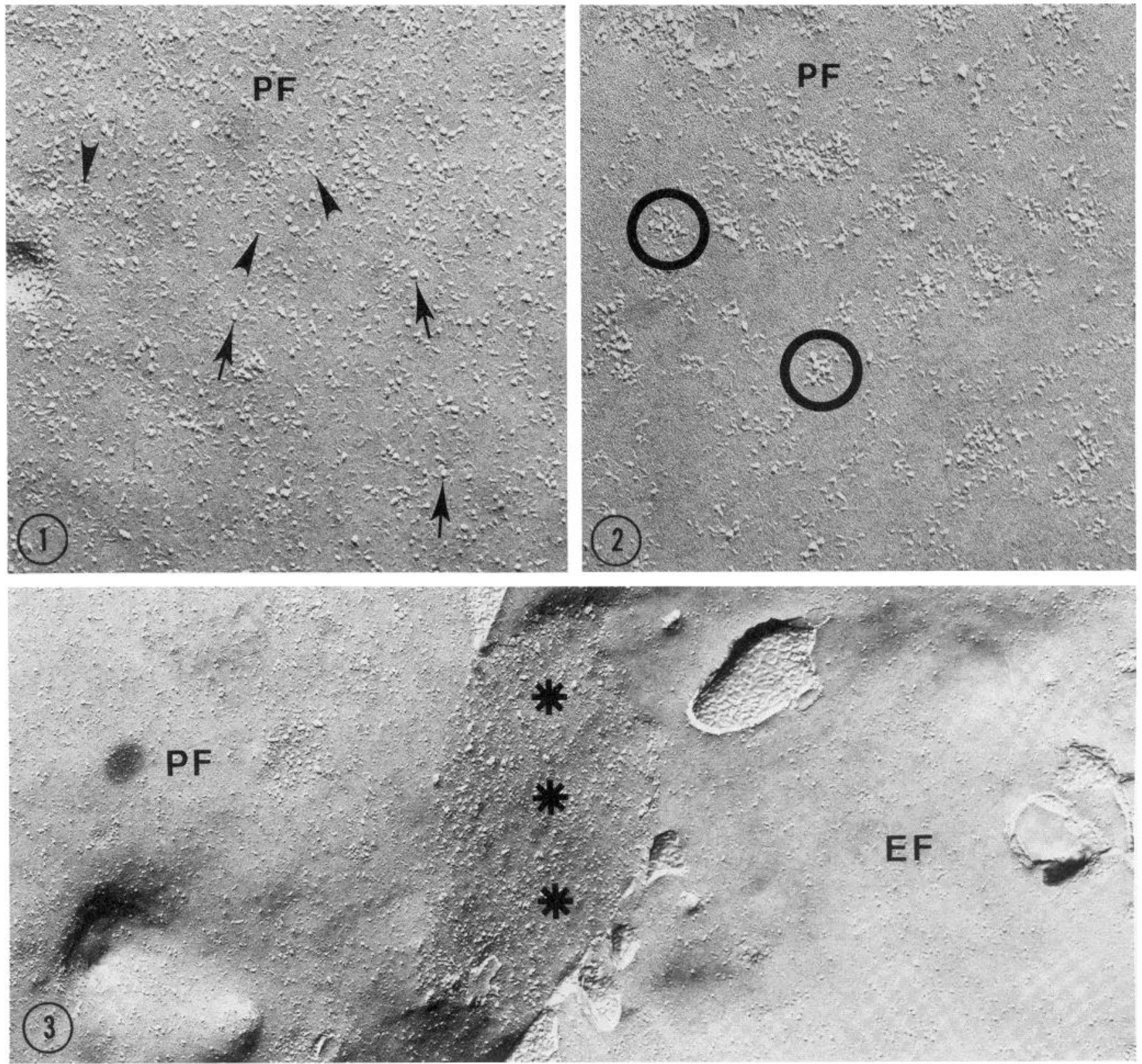

Figure 1. The plasmalemmal $\mathrm{P}$ face $(P F)$ of a freshly isolated $B 3$ cell shows globular (arrows) and elongated (arrowheads) particles similar to those seen in oligodendrocytic plasma membranes in situ. Magnification $\times 77,500$.

Figure 2. The plasmalemmal $\mathrm{P}$ face $(P F)$ of a freshly isolated $B 3$ oligodendrocyte shows patching (see circles) of elongated and globular particles. Magnification $\times 77,500$.

Figure 3. The plasmalemmal $\mathrm{P}$ face $(P F)$ of a freshly isolated $B 3$ oligodendrocyte shows an enrichment of elongated and globular particles (asterisks) where it apposes the $\mathrm{E}$ face $(E F)$ of a neighboring oligodendrocyte. Magnification $\times 49,500$.

on the $\mathrm{E}$ face (Fig. 7). The tight junctional arrays run parallel to one another (Fig. 6) or anastomose at points (Fig. 7).

\section{Thin section electron microscopy of B3f oligodendrocytes}

Thin sections of pelleted B3f oligodendrocytes show rounded cell bodies without cell processes and some cell debris (Fig. 8). The cytoplasm is of varying electron density and contains numerous microtubules, polyribosomes, cisterns of endoplasmic reticulum, mitochondria, and vacuoles, but no intermediate filaments (Fig. 9). In the denser cells, the chromatin is clumped, whereas in the lighter cells, it is evenly distributed. The cells resemble oligodendrocytes in the brain of young mammals (Mori and Leblond, 1970). The intracellular vacuoles presumably are an expression of cell damage produced by the isolation procedure. Whereas some of the vacuoles are delimited by a single membrane, others consist of double membranes (Fig. 9, arrowheads), which at points appear conspicuously electron dense. As is seen in the inset of Figure 9, electron-dense material adheres to the inner and outer membranes of the double-walled vacuoles. The electron density and the close spacing of the membranes in these vacuoles resemble internalized gap junctions described in other kinds of cells (Albertini and Anderson, 1975; Gilula, 1976; Raviola et al., 1980). B3f oligodendrocytes in the pellet are apposed to one another at points (arrows in Figs. 8 and 9). Typical junctional specializations, however, are not discerned at these sites of contact. Moreover, many of the cells show blebs 0.3 to $1 \mu \mathrm{m}$ in diameter adhering to their surface (Fig. 9, asterisks). Whereas some of these blebs have a completely electron-lucent content, others contain a few mem- 

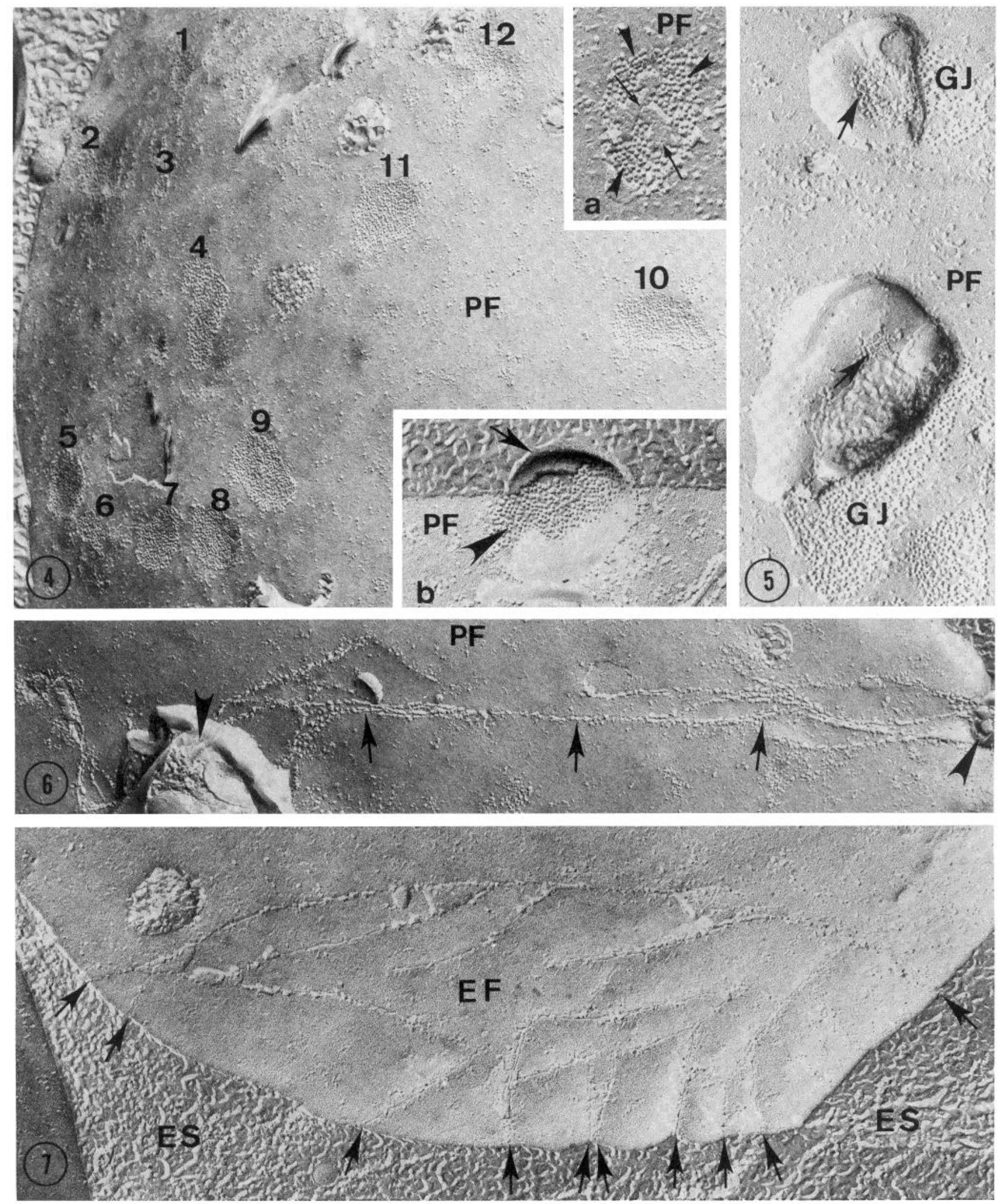

Figure 4. The plasmalemmal $\mathrm{P}$ face $(P F)$ of a freshly isolated $B 3$ oligodendrocyte shows numerous gap junctions (numbered 1 to 12 ) resembling those found in oligodendrocytes in situ. Magnification $\times 49,500$. Inset a shows the plasmalemmal $\mathrm{P}$ face $(P F)$ of a freshly isolated $B 3$ oligodendrocyte with a patch of gap junctional particles (arrowheads) partly covered by fragments of the $\mathrm{E}$ face of an adjoined plasma membrane bleb. Gap junctional pits (arrows) are evident on the $\mathrm{E}$ face fragments. Magnification $\times 109,000$. Inset $b$ shows the plasmalemmal $\mathrm{P}$ face $(P F)$ of a freshly isolated B3 oligodendrocyte with a gap junctional particle patch (arrowhead) facing a membranous bleb (arrow). Magnification $\times$ 85,000 .

Figure 5. Two astrocytic plasma membrane blebs identified by orthogonal particle assemblies (arrows) are attached to gap junction (GJ) particle aggregates on the plasmalemmal $P$ face $(P F)$ of a freshly isolated $B 3$ oligodendrocyte. Magnification $\times 93,000$.

Figure 6. The plasmalemmal $\mathrm{P}$ face $(P F)$ of a $B 3$ oligodendrocyte shows tight junctional arrays (arrows) with attached fragments of another plasma membrane (arrowheads). Magnification $\times 49,500$.

Figure 7. The plasmalemmal $\mathrm{E}$ face $(E F)$ of a $B 3$ oligodendrocyte shows numerous tight junctional grooves (arrows) facing extracellular space $(E S)$. Magnification $\times 69,000$. 

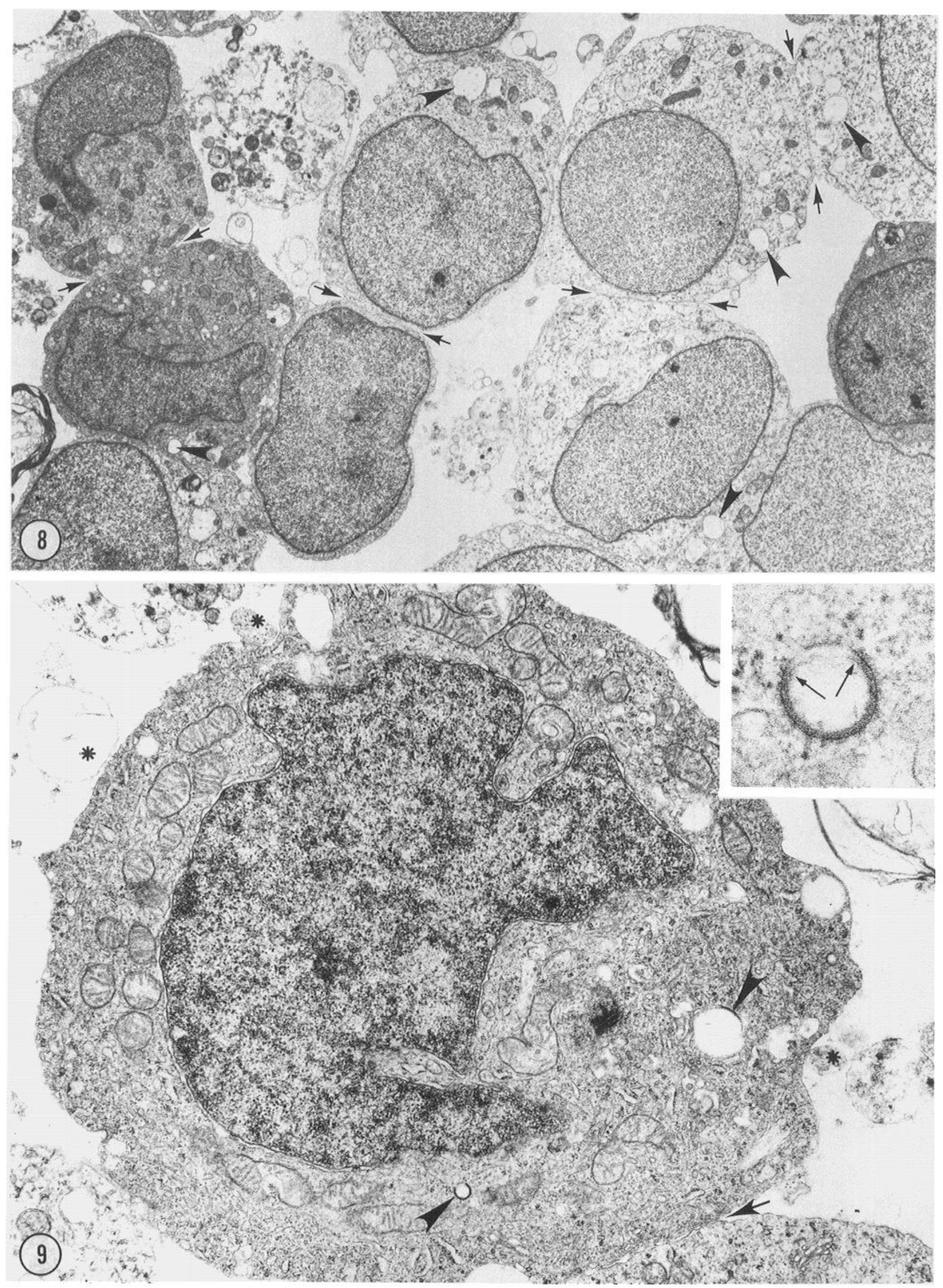

Figure 8. Thin section electron micrograph of a pellet of B3f cells grown for 3 days under conditions of nonattachment. The cells show varying electron density, resembling oligodendrocytes in the brain of young animals. Large, empty intracellular vacuoles are indicated by arrowheads. Adhesion sites between cells are indicated by arrows. Magnification $\times 5,000$.

Figure 9. Thin section of a moderately electron dense B3f oligodendrocyte. The cytoplasm contains microtubules, mitochondria, polyribosomes, cisterns of endoplasmic reticulum, and several vacuoles, but no intermediate filaments. The arrowheads point to the sites where the membranes of two vacuoles appear conspicuously electron dense. An adhesion site to a neighboring cell is indicated by an arrow. Asterisks mark attached blebs. Magnification $\times 17,500$. Inset, Detail of a double-walled vacuole interpreted as an internalized gap junction. The arrows point to sites of the double membrane vesicle where the two membranes separate. Magnification $\times 99,000$. 

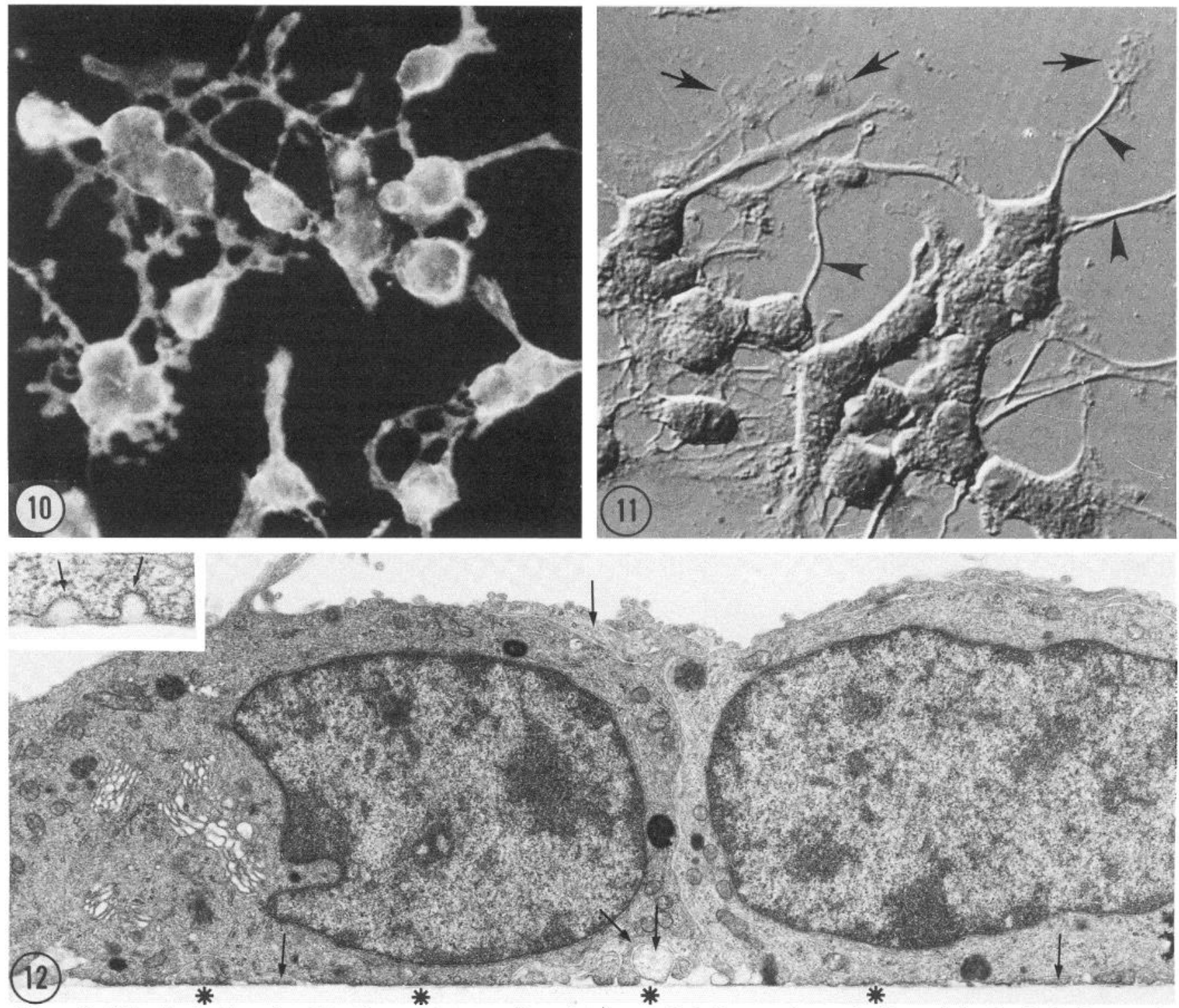
米

using a monoclonal antibody to galactocerebroside. Magnification $\times 900$.

Figure 11. Normarski optics reveal B3fa oligodendrocytic cell bodies ( 3 weeks after plating), at the border of a monolayer, that adhere to the dish and emanate numerous cylindrical (arrowheads) and flattened (arrows) processes. Magnification $\times 900$.

Figure 12. Thin section of B3fa oligodendrocytes ( 3 weeks after plating) cut perpendicular to the monolayer. Oligodendrocytic cell bodies and processes (arrows) are closely apposed to the dish (asterisks) and to one another. Magnification $\times 11,000$. Inset, Coated pits (arrows) of the oligodendrocytic plasma membrane facing the dish. Magnification $\times 45,000$.

branous profiles in a watery milieu or in a flocculent matrix (Fig. 9). As is demonstrated by freeze-fracturing of B3 oligodendrocytes, most of these blebs are derived from astrocytic and oligodendrocytic plasma membranes sheared from the parent cells by the isolation procedure.

\section{Cultures of B3fa oligodendrocytes}

Light microscopic and thin section electron microscopy. After 1 to 5 weeks, the polylysine-coated dishes are covered by a nearly homogeneous population of oligodendrocytes, as indicated by the intense fluorescence of more than $95 \%$ of the cells and their processes when stained with a monoclonal antibody to galactocerebroside (Fig. 10), an oligodendrocyte-specific plasma membrane component (Raff et al., 1978). The cells also stain for myelin basic protein (not shown), another oligodendrocytic marker (Sternberger et al., 1978; Mirsky et al., 1980; Szuchet et al., 1980b). The attached oligodendrocytes form mono- and multilayers where the cells are in close contact with one another and frequently align in rows. Figure 11 shows the architecture of these oligodendrocytes after 1 week in culture. The cells emanate numerous long cylindrical processes which often flatten at their ends into expansive flaps apposing the dish (Fig. 11, arrows).

Thin section electron microscopy shows a homogeneous population of cell bodies of moderate electron density, containing numerous microtubules, electron dense bodies, and a prominent Golgi apparatus (Fig. 12). Intermediate filaments (not shown), absent in the freshly isolated cells, are also present in the cytoplasm and become progressively more prominent in the older cultures. The nature of these filaments is currently under investigation. A typical monolayer shows cell body plasma membranes attached directly to the culture dish and numerous cylindrical and flattened processes fitting themselves underneath (Fig. 12, arrows) and between the oligodendrocytic cell 

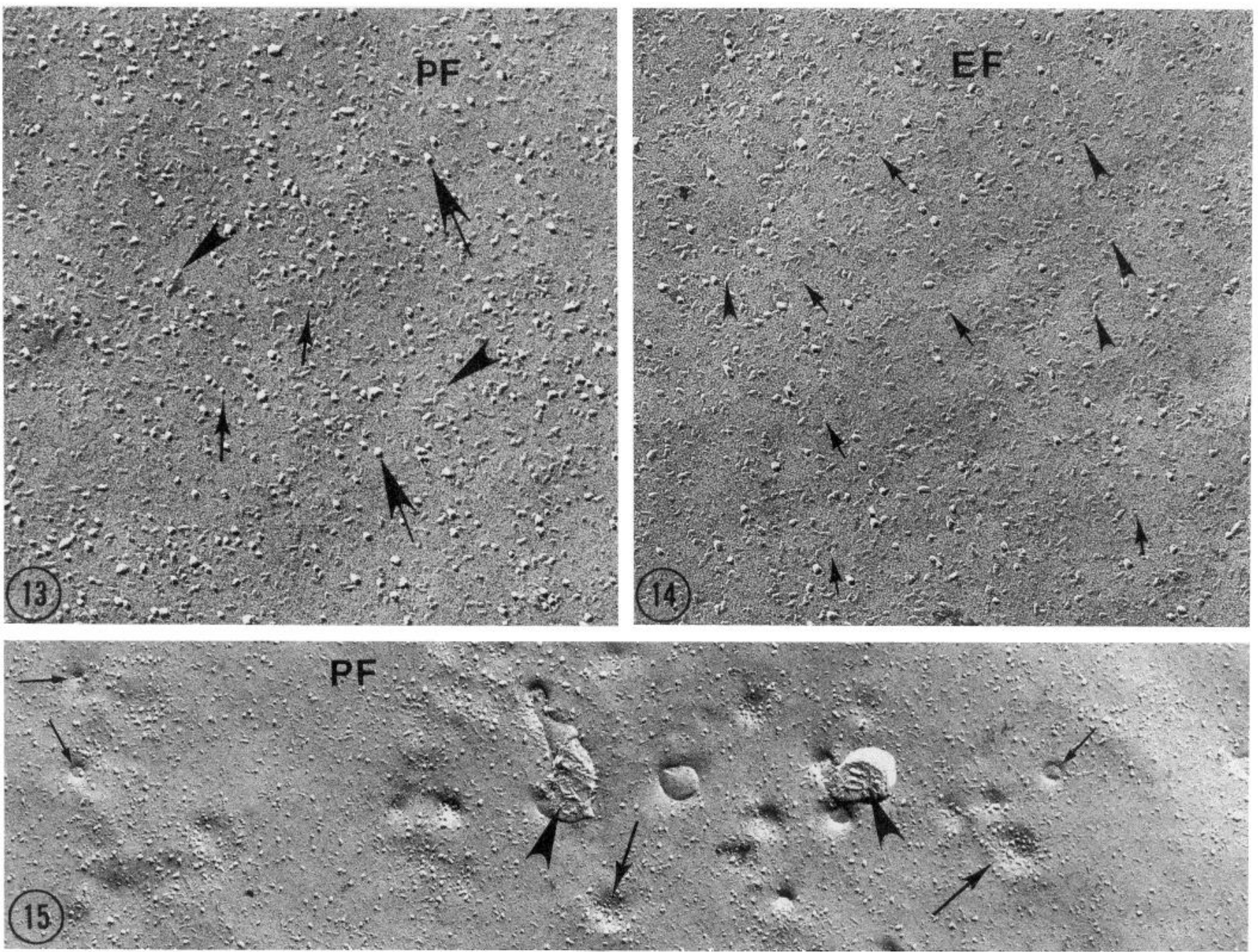

Figure 13. The plasmalemmal P face $(P F)$ of a $B 3 f a$ oligodendrocyte (3 weeks after plating) contains a heterogeneous population of particles: short globular particles of small diameter (small arrows), tall globular particles of large diameter (large arrows), and elongated particles (arrowheads). Magnification $\times 108,500$.

Figure 14. The plasmalemmal E face $(E F)$ of a B3fa oligodendrocyte (3 weeks after plating) shows a few round (arrows) and elongated (arrowheads) pits. Scattered large globular particles and numerous elongated particles are also present. Magnification $\times 108,000$.

Figure 15. The plasmalemmal $\mathrm{P}$ face $(P F)$ of a $B 3 f a$ oligodendrocytic cell body (3 weeks after plating) shows small dimples ( $(s m a l l$ arrows) and larger shallow depressions (large arrows) containing aggregates of predominantly globular particles. The arrowheads indicate regions of the replica corresponding to the ice-dish interface. Magnification $\times 59,500$.

bodies. Coated pits are frequently observed on oligodendrocytic plasma membranes apposing both the dish (Fig. 12, inset) and other oligodendrocytic plasma membranes.

Freeze-fracture electron microscopy. The fracture plane usually passes close to the culture dish and exposes large intramembrane vistas of cell bodies and processes. The $\mathrm{P}$ faces of oligodendrocytic plasma membranes after 1 to 5 weeks in culture show numerous evenly distributed intramembrane particles whose profiles and densities do not change substantially over time. Pilot particle counts and measurements were done on a small sample of oligodendrocytes 3 weeks after plating (six micrographs of P and E fracture faces; an area of $10 \mu \mathrm{m}^{2} /$ micrograph). The intramembrane particles are classified as globular and elongated (Fig. 13). The globular particles are further subdivided into tall particles of large diameter (10.0 to $18.0 \mathrm{~nm}$; Fig. 13 large arrows) and short particles of small diameter (3.0 to $9.0 \mathrm{~nm}$; Fig. 13, small arrows), which occur roughly in a $1: 1$ ratio. The elongated particles measure 7.0 to $34.0 \mathrm{~nm}$ in length and 3.0 to $9.0 \mathrm{~nm}$ in width. Elongated particles 10.0 to $18.0 \mu \mathrm{m}$ long are most frequent, representing approximately two-thirds of the elongated particles.
The average density of large and small globular $\mathrm{P}$ face particles is approximately $1000 / \mu \mathrm{m}^{2}$. The average density of elongated $\mathrm{P}$ face particles is $800 / \mu \mathrm{m}^{2}$. Compared to $\mathrm{P}$ faces, the $\mathrm{E}$ faces (Fig. 14) of oligodendrocytic plasma membranes show fewer large globular particles but a higher density of small globular and elongated particles. The density of large and small globular particles in E faces is roughly $1100 / \mu \mathrm{m}^{2}$ and that of elongated particles, $1000 / \mu \mathrm{m}^{2}$. In addition to $\mathrm{E}$ face particles, round and elongated pits similar to those seen in $\mathrm{P}$ faces are present (Fig. 14, arrows and arrowheads).

Plasma membrane $\mathrm{P}$ faces of oligodendrocytic cell bodies and processes often display numerous small dimples (35 $\mathrm{nm}$ in diameter) and larger shallow depressions (100 $\mathrm{nm}$ in diameter), presumably corresponding to coated pits and containing aggregates of predominantly globular particles and some elongated particles (Fig. 15). These particles are similar in size to the variety of evenly distributed $\mathrm{P}$ face particles shown in Figure 13.

Linear arrays that resemble the peculiar tight (or occluding) junctions of myelin (Schnapp and Mugnaini, 1978) and to some extent also the occluding junctions of Sertoli cells (Fawcett, 

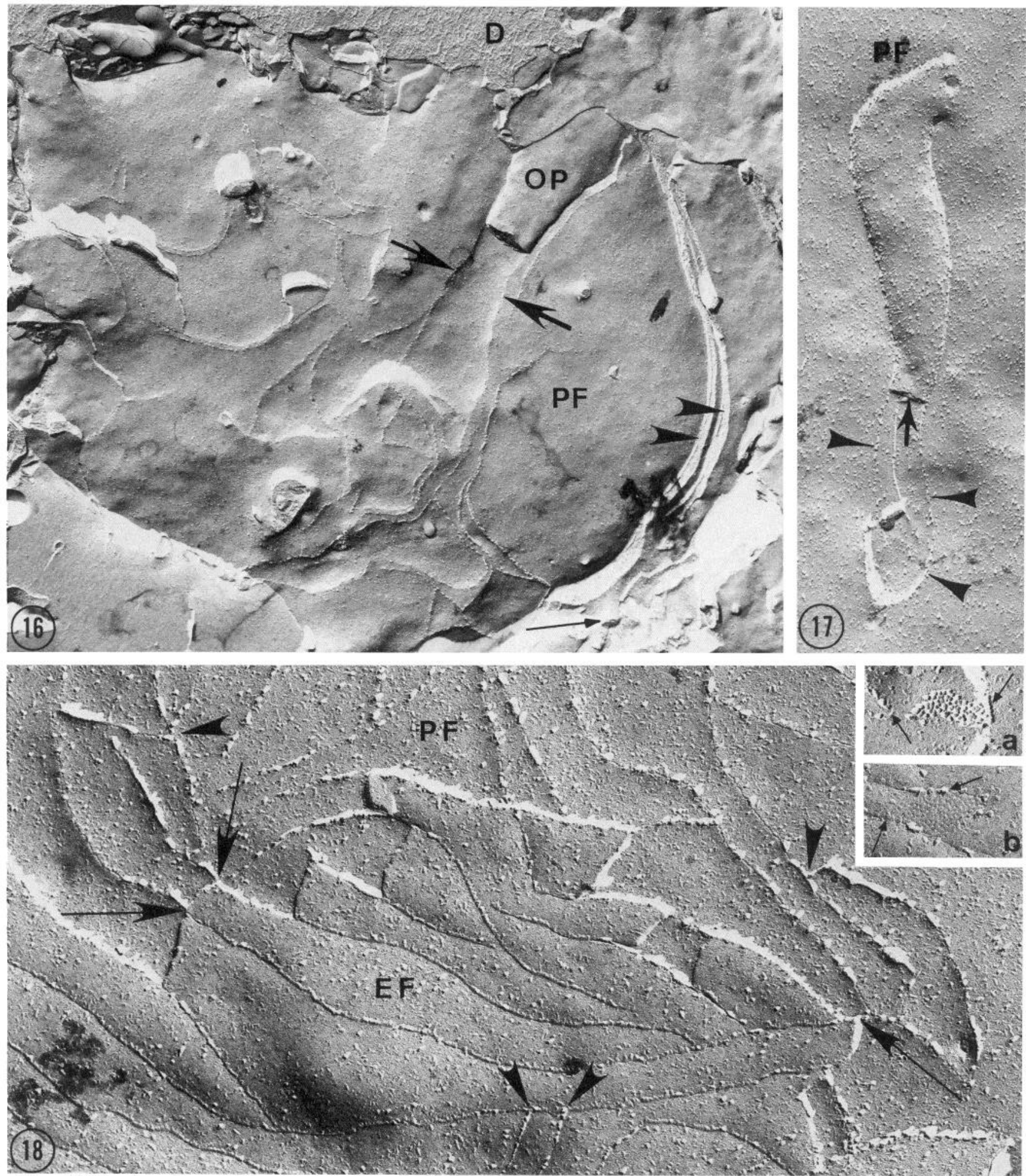

Figure 16. The plasmalemmal $\mathrm{P}$ face $(P F)$ of a $B 3 f a$ oligodendrocytic cell body (2 weeks after plating) with meandering tight junctional strands and particles. A cylindrical oligodendrocytic process $(O P)$ lies within a furrow on the cell body bordered on either side by tight junctional arrays (large arrows). Flattened processes are also apposed to each other and to the cell body (arrowheads). One of the flat processes is seen arising from a cylindrical profile (samll arrow). The ice-dish interface is labeled $(D)$. Magnification $\times 24,500$.

Figure 17. P face view of the process of a B3fa oligodendrocyte (1 week after plating) forms tight junctions (arrowheads) with the parent cell body. The arrow indicates the cross-fractured cytoplasm of the process. Magnification $\times 34,500$.

Figure 18. The plasmalemmal $\mathrm{E}$ face $(E F)$ of the flattened process of a $B 3 f a$ oligodendrocyte (1 week after plating) is seen facing the $\mathrm{P}$ face of a cell body $(P F)$. The $\mathrm{E}$ face shows tight junctional arrays aligned at points (arrows) with the $\mathrm{P}$ face arrays. Tight junctions are often anastomosed (arrowheads). Note that grooves predominate on the $\mathrm{E}$ face and strands predominate on the $\mathrm{P}$ face. Magnification $\times 69,500$. Insets $a$ and $b$, Gap junctional particles $(a)$ and pits $(b)$ in between closely spaced tight junctional strands and grooves $(a r r o w s)$. Magnification $\times 94,000$. 


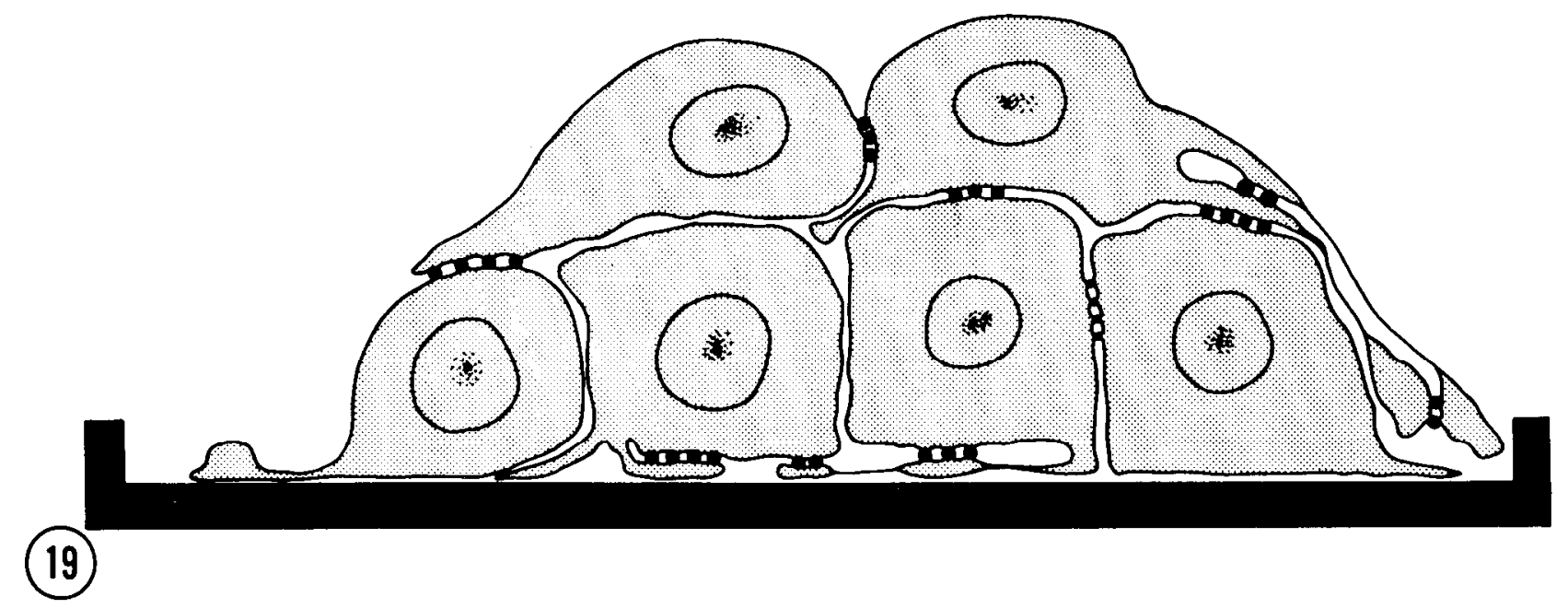

Figure 19. Schematic representation showing the distribution of tight junctions (dots) formed between cell bodies and processes of plated oligodendrocytes.

1975) occur frequently at sites of contact between the oligodendrocytes 1 week after plating and become progressively more numerous with time in culture. In $\mathrm{P}$ faces, these junctions usually appear as grooves interrupted by segments of strands and/or rows of particles (Figs. 16 and 18). Grooves may be absent along portions of the arrays (Fig. 17). On the E face tight junctional strands and particles interrupted by segments of grooves often predominate (Fig. 18). Thus, the distribution of tight junctional components is partly inverted compared to those of freshly isolated, $B 3$ oligodendrocytes and of oligodendrocytes in situ.

Tight junctions between a cell body and a flattened process are more frequently anastomosed (Fig. 18) than are those between a cell body and a cylindrical process (Fig. 16). Often a single linear tight junctional array borders the area of contact between a cylindrical process and a cell body (Fig. 16, arrows). Tight junctions are also formed by oligodendrocytic processes reflected on their parent cell body (Fig. 17).

The plasma membranes of 1 - to 5 -week plated oligodendrocytes do not display the numerous patches of gap junctional particles in freeze-fracture replicas that are apparent both in situ and in freshly isolated cells. However, in two micrographs from a 3-week culture, we have identified small aggregates of 9-nm particles ( $P$ face) or pits ( $E$ face) apparently representing gap junctions (Fig. 18, insets $a$ and $b$ ). These small gap junctions are located between closely spaced tight junctional strands or grooves (Fig. 18, arrows in insets), a feature observed in certain ependymal cells, pituicytes, and cells of the choroid plexus (reviewed by Sandri et al., 1982).

\section{Discussion}

In this study, we have isolated, purified, and cultured ovine oligodendrocytes for thin section and freeze-fracture electron microscopy to study the internal structure of their plasma membranes, especially at sites of mutual contact.

\section{Freshly isolated B3 and B3f oligodendrocytes}

Freeze-fracture indicates that the freshly isolated oligodendrocytes possess relatively well preserved plasma membranes, with intramembrane particle density, ratio of globular to elongated particles and fracture face repartition similar to those in situ. Patching of intramembrane particles is seen in only some of the cells. Thus, the combined enzymatic and mechanical tissue disruption affords a considerable cellular preservation, in spite of the fact that oligodendrocytes are deprived of their cell processes and continuous myelin sheaths. The two types of oligodendrocytic cell junctions, gap junctions and tight junctions (the former established in situ with astrocytes; the latter, with other oligodendrocytes), are also recognized in the freshly isolated oligodendrocytes. It appears that many oligodendrocytic gap junctions are preserved during the isolation procedure by tearing off the astrocytic partner cell plasma membrane, which then reseals to form a plasmalemmal bleb, as is seen in other dissociated epithelial cells (Amsterdam and Jamieson, $1972,1974)$. Although the step-by-step process of cell recovery from the isolation procedure remains to be studied, thin section electron microscopy of pelleted $B 3 f$ oligodendrocytes suggests that the gap junctions are removed by internalization, a phenomenon observed in cells undergoing various kinds of metabolic changes (Albertini and Anderson, 1975; Larsen, 1977; Peracchia, 1980; Raviola et al., 1980). The inter-oligodendrocytic tight junctions, by contrast, are loosened during dissociation of the partner cells with minimal formation of membrane blebs, an effect attributable to the absence of $\mathrm{Ca}^{2+}$ in the isolation media (Meldolesi et al., 1978; Martinez-Palomo et al., 1980). The fate of the tight junctional arrays in the plasma membranes of freshly isolated oligodendrocytes remains to be determined. Internalization and lysosome degradation, or redeployment and reutilization, seem to be involved to varying degrees in different epithelia (Staehelin, 1973, 1974; Amsterdam and Jamieson, 1974; Dermietzel et al., 1977; Lane and Swales, 1978; Meldolesi et al., 1978; Polak-Charcon and BenShaul, 1979; Porvaznik, 1979; Martinez-Palomo et al., 1980; Meza et al., 1980; Lane, 1981). The aggregates of isolated B3f oligodendrocytes, grown for 3 days under conditions of nonattachment, do not appear to be junctionally connected to onc another. Their close cell-cell appositions presumably correspond to the sites of mutual contact already apparent in pelleted B3 oligodendrocytes. These sites are characterized by enrichment of intramembrane particles. Such an enrichment of intramembrane particles indicates that the adjoining plasma membranes of freshly isolated oligodendrocytes undergo some form of interaction involving membrane components.

\section{B3fa oligodendrocytes}

Autoradiographic study of B3fa oligodendrocytic cultures incubated with tritiated thymidine (S. S. Szuchet, unpublished observations) indicate that mitotic activity is very low, and we conclude that most of the cells in the 1 - to 5-week plated cultures represent the original population of the freshly isolated $B 3 f$ oligodendrocytes. Our results indicate that plasma membranes of cultured oligodendrocytes closely resemble plasma 
membranes of oligodendrocytes in situ (Massa and Mugnaini, 1982 ) with respect to types of oligodendrocytic intramembrane particles. In addition, plasma membranes of oligodendrocytes in vitro interact with one another at sites of contact in a fashion similar to the interaction of those in situ by forming tight junctions between both cell bodies and processes. Since tight junctions are much more numerous in cultured B3fa oligodendrocytes than in freshly isolated $B 3$ cells, many of these junctions must be formed de novo. These observations suggest that isolated oligodendrocytes develop and maintain specialized plasma membranes, perhaps with functional properties similar to those in situ. Biochemical evidence (e.g., overall lipid metabolism; Szuchet et al., 1983) supports this notion. The appearance of cytoplasmic intermediate filaments, however, indicates some degree of cellular transformation that remains to be explored in detail.

Density and repartition of intramembrane particles and tight junctional components. The particulate components in the freeze-fracture faces of $B 3 f a$ oligodendrocytes show conspicuous differences in densities and repartition compared to those of both freshly isolated and in situ oligodendrocytes. This indicates that attachment and culturing bring about subtle changes in the plasma membranes of these cells. Plasma membranes of feline oligodendrocytes in situ have approximately $900 \mathrm{P}$ face particles $/ \mu \mathrm{m}^{2}$ and $400 \mathrm{E}$ face particles $/ \mu \mathrm{m}^{2}$ (Massa and Mugnaini, 1982). Similar values are obtained from freshly isolated ovine oligodendrocytes (P faces, $700 / \mu \mathrm{m}^{2}$, and $\mathrm{E}$ faces, $400 /$ $\left.\mu \mathrm{m}^{2}\right)$. Preliminary counts in 3-week-old cultures of attached oligodendrocytes indicate substantial increases and a shift in repartition of intramembrane particles: the intramembrane $P$ face and $E$ face particle densities increase to $1800 / \mu \mathrm{m}^{2}$ and $2100 / \mu \mathrm{m}^{2}$, respectively. Furthermore, tight junctions become more numerous with time in culture, and the $\mathrm{P}$ face/ $\mathrm{E}$ face repartition of their components appears partly inverted, with grooves present on the $\mathrm{P}$ face at frequent points along the arrays. Differences in parameters of fixation, cryoprotection, and freeze-cleaving (Ornberg and Reese, 1979; Satir and Satir, 1979; Kachar and Reese, 1982a) or metabolic changes and complex membrane-substrate interactions could be involved. Alternatively, if it is assumed that the intramembrane particulate components have destinations other than and in addition to the plasma membrane (e.g., myelin), then aberrant transport and/or control due to the absence of a bona fide recipient may account for their excessive accumulation within the plasma membrane and for their different repartition. Accurate evaluation of intramembrane particle densities over time, and especially during the first week in culture, thus remains an interesting proposition. However, since the procedure of Pauli et al. (1977) usually exposes the plasma membranes of cells attached to the substrate, it will be difficult to obtain a random sample from all of the oligodendrocytes in the culture, particularly where these are arranged in multilayers.

Dimples and shallow depressions. Clusters of particles are present within shallow depressions of $P$ faces of oligodendrocytic plasma membranes. In addition, $35-\mathrm{nm}$ dimples or stomata are frequent. We interpret these features as progressive stages in the formation of coated pits and vesicles. Similar features have been described in many types of cells and are thought to be involved in plasma membrane recycling (Heuser and Reese, 1979; Pearse and Bretscher, 1981) or receptormediated endocytosis (Steinman et al., 1983).

Oligodendrocytic cell junctions. As mentioned, mature oligodendrocytes in situ form numerous gap junctions (250 to $500 /$ cell) at sites of contact, with astrocytic cell bodies and processes, whereas inter-oligodendrocytic contacts are marked by tight junctions (Massa and Mugnaini, 1982). Linear tight junctions also occur within the myelin sheath: at the outer and inner mesaxons, between paranadol loops, and between adjacent turns of the myelin lamella (reviewed by Schnapp and Mugnaini, 1978). As expected, tight junctions between isolated and cultured ovine oligodendrocytes abound, whereas inter-oligodendrocytic gap junctions are rare or absent. This situation is represented schematically in Figure 19. In contrast, Gonatas et al. (1982), in thin sections of 2- to 3-week cultures of purified rat oligodendrocytes, observed numerous large, seven-layered and pentalaminar junctions, which they interpreted as gap junctions and tight junctions, respectively. Gap junctions were also observed in thin sectioned floating clusters of purified ovine oligodendrocytes by Wollman et al. (1981), although junctional complexes were not apparent after plating. Such results would appear partly at odds with this study. However, Gonatas and co-workers (1982) purified the oligodendrocytes with a different procedure; Wollman and co-workers (1981) used a mixture of band II and band III cells, thus including not. only the B3f cells used in this study but also other cells not included in the present material. Moreover, classification of oligodendrocytic cell junctions in thin sections may be equivocal (see discussion in Massa and Mugnaini, 1982). In spite of such reservations, it remains possible that species differences, cell separation, and culture conditions may modify junction formation by purified oligodendrocytes in vitro. Gap junctional particles, if present in the plasma membrane of our cultured oligodendrocytes in solitary form, may remain largely undetected by freeze-fracture criteria. In consideration of the latter point, conditions that promote formation of patches of gap junctional particles in other types of cell (Kachar and Reese, 1982b) could be explored to ascertain whether formation of such junctions can be reproducibly obtained in cultured oligodendrocytes.

Apical tight junctions in epithelial linings are generally related to compartmentation of tissue spaces and the maintenance of polarized membrane macromolecular domains. Tight junctions maintain extracellular compartments (Taub and Saier, 1979) and polarity of membrane proteins of such epithelia also in vitro (Rodriguez-Boulan and Sabatini, 1978; Herzlinger and Ojakian, 1984).

The functions of the linear tight junctions between oligodendrocytes are difficult to ascertain because they are irregularly distributed in the plasma membrane and, thus, are not related to a distinct polarity. Since these junctions are sparsely anastomosed, they must produce only partial occlusions of the extracellular compartment and may represent a special class of leaky tight junctions (Claude and Goodenough, 1973). De novo formation of numerous tight junctions between cell bodies and processes of plated oligodendrocytes indicates that this property can be expressed, in the absence of both neurons and astrocytes, over a large extent of the oligodendrocytic plasma membrane and may represent the attempt by these cells to reform myelin-like plasma membrane associations. Regulation of tight junction formation in oligodendrocytes and the nature of the components involved in such junctional macromolecular assemblies (Kachar and Reese, 1982a; Griepp et al., 1983; Stevenson and Goodenough, 1984) may thus be studied advantageously in vitro.

\section{References}

Albertini, D. F., and E. Anderson (1975) Structural modifications of lutein cell gap junctions during pregnancy in the rat and the mouse. Anat. Rec. 181: 171-194.

Amsterdam, A., and J. D. Jamieson (1972) Structural and functional characterization of isolated pancreatic exocrine cells. Proc. Natl. Acad. Sci. U. S. A. 69:; 3928-3932.

Amsterdam, A., and J. D. Jamieson (1974) Studies on dispersed pancreatic exocrine cells. I. Dissociation technique and morphological characterization of separated cells. J. Cell Biol. 63: 1037-1056.

Anders, J. J., and M. W. Brightman (1979) Assemblies of particles in 
the cell membranes of developing mature and reactive astrocytes. J. Neurocytol. 8: 777-795.

Anders, J. J., and M. W. Brightman (1981) Orthogonal particle assemblies of intramembranous particles-an attribute of the astrocyte. In Eleventh International Congress of Anatomy: Glial and Neuronal Cell Biology, S. Federoff, ed., pp. 21-35, Alan R. Liss, Inc., New York.

Branton, D., S. Bullivant, N. B. Gilula, M. J. Karnovsky, II. Moor, K. Muhlethaler, D. H. Northcote, L. Packer, B. Satir, P. Satir, V. Speth, L. A. Staehelin, R. L. Steere, and R. S. Weinstein (1975) Freezeetching nomenclature. Science 190: 54-56.

Brightman, M. W., and T. S. Reese (1969) Junctions between intimately apposed cell membranes in the vertebrate brain. J. Cell Biol. 40: 648-677.

Claude, P., and D. A. Goodenough (1973) Fracture faces of zonulae occludentes from "tight and leaky" epithelia. J. Cell Biol. 58: 390_ 400.

Cullen, M. J., and R. L. Gulley (1980) Freeze-fracture studies of the macromolecular organization of glial membranes. Trends Neurosci. 3: $113-116$.

Dermietzel, R. (1974) Junctions in the CNS of the cat. III. Gap junctions and membrane-associated orthogonal particle complexes (MOPC) in astrocytic membranes. Cell Tissue Res. 149: 121-135.

Dermietzel, R., K. Meller, W. Tetzlaff, and M. Wallsch (1977) In vivo and in vitro formation of the junctional complex in choroid epithelium. Cell Tissue Res. 181: 427-441.

Dermietzel, R., D. Schunke, and A. Leibstein (1978) The oligodendrocytic junctional complex. Cell Tissue Res. 193: 61-72.

Fawcett, D. W. (1975) Ultrastructure and function of the Sertoli cells. In Handbook of Physiology. Section 7: Endrocrinolgy. Vol. V: Male Reproductive System. D. W. Hamilton and R. O. Greep, eds., pp. 2155, American Physiological Society, Washington, D.C.

Friedrich, V. L., P. T. Massá, and E. Mugnaini (1980) Fine structure of oligodendrocytes and central myelin sheaths. In Search for the Cause of Multiple Sclerosis and Other Chronic Diseases of the Central Nervous System, A. Boese, ed., pp. 27-46, Verlag Chemie, Weinheim.

Gebicke-Harter, P. J., H. H. Althaus, P. Schwartz, and V. Neuhoff (1981) Oligodendrocytes from postnatal cat brain in cell culture. I. Regeneration and maintenance. Dev. Brain Res. 1: 497-518.

Gilula, N. B. (1976) Gap junctions and cell communication. In International Cell Biology 1976-1977, B. R. Brinkley and K. R. Porter, eds., pp. 61-69, The Rockefeller University Press, New York.

Gonatas, N. K., M. Hirayama, A. Stieber, and D. H. Silberberg (1982) The ultrastructure of isolated rat oligodendroglial cell cultures. J. Neurocytol. 11: 997-1008.

Griepp, E. B., W. J. Dolan, E. S. Robbins, and D. D. Sabatini (1983) Participation of plasma membrane proteins in the formation of tight junctions by cultured epithelial cells. J. Cell Biol. 96: 693-702.

Hatton, J. D., and M. H. Ellisman (1981) The distribution of orthogonal arrays and their relationship to intercellular junctions in neuroglia of the freeze-fractured hypothalamo-neurohypophyseal system. Cell Tissue Res. 215: 309-324.

Herzlinger, D. A., and E. K. Ojakian (1984) Studies on the development and maintenance of epithelial cell surface polarity with monoclonal antibodies. I. Cell Riol. 98: 1777-1787.

Heuser, J. E., and T. S. Reese (1979) Synaptic vesicle exocytosis captured by quick freezing. In Fourth Intensive Study Program in the Neurosciences, F. O. Schmitt and F. G. Worden, eds., pp. 573600 , MIT Press, Cambridge, MA.

Kachar, B., and T. S. Reese (1982a) Evidence for the lipidic nature of tight junction strands. Nature 296: 464-466.

Kachar, B., and T. S. Reese (1982b) Rapid formation of gap junctions induced by treatment with dilute glycerol. J. Cell Biol. 95: 102a.

Landis, D. M. D., and T. S Reese (1974) Arrays of particles in freezefractured astrocytic membranes. J. Cell Biol. 60: 316-320.

Lane, N. J. (1981) 'T'ight junctions in arthropod tissues. Int. Rev. Cytol. 73: $244-318$.

Lane, N. J., and L. S. Swales (1978) Changes in the blood-brain barrier of the central nervous system in the blowfly during development, with special reference to the formation and disaggegation of gap and tight junctions. Dev. Biol. 62: 415-431.

Larsen, W. J. (1977) Structural diversity of gap junctions. A review. Tissue Cell 9: 373-394.

Lisak, R. P., D. W. Pleasure, D. H. Silberberg, M. C. Manning, and T. Saida (1981) Long term culture of bovine oligodendroglia isolated with a Percoll gradient. Brain Res. 223: 107-122.
Mack, S. R., and S. Szuchet (1980) Differentiated functions of oligodendrocytes in long term culture. Trans. Am. Soc. Neurochem. 11: 104a.

Martinez-Palomo, A., I. Meza, G. Beaty, and M. Cereijido (1980) Experimental modulation of occluding junctions in a cultured transporting epithelium. J. Cell Biol. 87: 736-745.

Massa, P. T., and E. Mugnaini (1982) Cell junctions and intramembrane particles of astrocytes and oligodendrocytes: A freeze-fracture study. Neuroscience 7: 523-538.

Massa, P. T., S. Szuchet, and E. Mugnaini (1983) Tight junctions and intramembrane particles of cultured oligodendrocytes. Biophys. J. 41: $69 \mathrm{a}$.

McCarthy, K. D., and J. DeVellis (1980) Preparation of separate astroglial and oligodendroglial cell cultures from rat cerebral tissue. J. Cell Biol. 85: 890-902.

Meldolesi, J., G. Castiglioni, R. Parma, N. Nassiver, and P. DeCamilli (1978) $\mathrm{Ca}^{++}$-dependent disassembly and reassembly of occluding junctions in guinea pig pancreatic acinar cells. Effect of drugs. J. Cell Biol. 79: 156-172.

Meza, I., G. Ibarra, M. Sabanero, A. Martinez-Palomo, and M. Cereijido (1980) Occluding junctions and cytoskeletal components in a cultured transporting epithelium. J. Cell Biol. 87: 746-754.

Mirsky, R., J. Winter, E. R. Abney, R. M. Pruss, J. Gavrilovic, and M. C. Raff (1980) Myelin-specific proteins and glycolipids in rat Schwann cells and oligodendrocytes in culture. J. Cell Biol. 84: 483494.

Mori, S., and C. Leblond (1970) Electron microscopic identification of of three classes of oligodendrocytes and preliminary study of their proliferative activity in the corpus callosum of young rats. J. Comp. Neurol. 139: 1-30.

Mugnaini, E. (1982) Membrane specializations in neuroglial cells and at neuron-glia contacts. In Neuronal-Glial Cell Interrelationships, T. A. Sears, ed., pp. 39-56, Dahlem-Konferenzen, Springer-Verlag, Berlin

Orkand, R. K. (1982) Signalling between neuronal and glial cells. In Neuronal-Glial Cell Interrelationships, T. A. Sears, ed., pp. 147-158, Dahlem-Konferenzen, Springer-Verlag, Berlin.

Ornberg, R. L., and T. S. Reese (1979) Artifacts of freezing in Limulus amebocytes. In Freeze-Fracture: Methods, Artifacts, and Interpretations, J. E. Rash and C. S. Hudson, eds., pp. 89-97, Raven Press, New York.

Pauli, B. V., R. S. Weinstein, L. W. Soble, and J. Alroy (1977) Freezefracture of monolayer cultures. J. Cell Biol. 72: 763-769.

Pearse, B. M. F., and M. S. Bretscher (1981) Membrane recycling by coated vesicles. Annu. Rev. Biochem. 50: 85-101.

Peracchia, C. (1980) Structural correlates of gap junction permiation. Int. Rev. Cytol. 66: 81-146.

Peters, A., S. L. Palay, and H. deF. Webster (1976) The Fine Structure of the Nervous System. The Neurons and Supporting Cells. W. B. Saunders Co., Philadelphia.

Polak-Charcon, S., and Y. Ben-Shaul (1979) Degradation of tight junctions in HT29, a human colon adenocarcinoma cell line. J. Cell Sci. 35: 393-402.

Porvaznik, M. (1979) Tight junction disruption and recovery after sublethal irradiation. Radiat. Res. 78: 233-250.

Raff, M. C., R. Mirsky, K. Fields, R. Lisak, S. Dorfman, D. Silberberg, M. Gregson, S. Liebowitz, and M. Kennedy (1978) Galactocerebroside: A specific cell surface antigenic marker for oligodendrocytes in culture. Nature 271: 813-816.

Raviola, E., D. A. Goodenough, and G. Raviola (1980) Structure of rapidly frozen gap junctions. J. Cell Biol. 87: 273-279.

Rodriguez-Boulan, E., and D. D. Sabatini (1978) Asymmetric budding of viruses in epithelial monolayers: A model system for study of epithelial polarity. Proc. Natl. Acad. Sci. U. S. A. 75: 5071-5075.

Sandri, C., J. M. Van Buren, and K. Akert (1982) Membrane morphology of the vertebrate nervous system. Prog. Brain Res. 46: 289323.

Satir, B. H., and P. Satir (1979) Partitioning of intramembrane particles during the freeze-fracture procedure. In Freeze-Fracture: Methods, Artifacts, and Interpretations, J. E. Rash and C. S. Hudson, eds., pp. 43-49, Raven Press, New York.

Schnapp, B., and E. Mugnaini (1978) Membrane architecture of myelinated fibers as seen by freeze-fracture. In Physiology and Pathobiology of Axons, S. G. Waxman, ed., pp. 83-123, Raven Press, New York. 
Staehelin, A. L. (1973) Further observations on the fine structure of freeze-cleaved tight junctions. J. Cell Sci. 13: 763-786.

Staehelin, A. L. (1974) Structure and function of intercellular junctions. Int. Rev. Cytol. 39: 191-283.

Steinman, R. M., J. S. Mellman, W. A. Muller, and Z. A. Cohn (1983) Endocytosis and the recycling of plasma membrane. A review. J. Cell Biol. 96: 1-27.

Sternberger, N. H., Y. Itoyama, M. W. Kies, and H. deF. Webster (1978) Immunocytochemical method to identify basic protein in myelin-forming oligodendrocytes of newborn rat C.N.S. J. Neurocytol. 7: 251-263.

Stevenson, B. R., and D. A. Goodenough (1984) Zonulae occludentes in junction complex-enriched fractions from mouse liver. Preliminary morphological and biochemical characterization. J. Cell Biol. 98: $1209-1221$.

Szuchet, S., and K. Stefansson (1980) In vitro behavior of isolated oligodendrocytes. Adv. Cell. Neurobiol. 1: 313-346.

Szuchet, S., and S. H. Yim (1984) Characterization of a subset of oligodendrocytes separated on the basis of selective adherence properties. J. Neurosci. Res. 11: 131-144.

Szuchet, S., B. G. W. Arnason, and P. E. Polak (1980a) Separation of ovine oligodendrocytes into two distinct bands on a linear sucrose gradient. J. Neurosci. Methods 3: 7-19.

Szuchet, S., K. Stefansson, R. L. Wollman, G. Dawson, and B. G. W. Arnason (1980b) Maintenance of two subpopulations of oligodendrocytes in long-term culture. Brain Res. 200: 151-164.

Szuchet, S., S. H. Yim, and S. Monsma (1983) Lipid metabolism of isolated oligodendrocytes maintained in long-term culture mimics events associated with myelinogenesis. Proc. Natl. Acad. Sci. U. S. A. 80: 7019-7023.

Tani, E., T. Itagaki, and M. Nakano (1977) Tight junctions of oligodendrocytes. Cell Tissue Res. 184: 139-142.

Tani, E., M. Nishiura, and N. Higashi (1973) Freeze-fracture studies of gap junctions of normal and neoplastic astrocytes. Acta Neuropathol. (Berl.) 26: 127-138.

Taub, M., and M. H. Saier (1979) An established but differentiated kidney epithelial cell line (MDCK). Methods Enzymol. 57: 552-560.

Wollman, R. L., S. Szuchet, J. Barlow, and M. Jerkovic (1981) Ultrastructural changes accompanying the growth of isolated oligodendrocytes. J. Neurosci. Res. 6: 757-769.

Yim, S. H., and S. Szuchet (1981) Differential behavior of oligodendrocyte subpopulations. Trans. Am. Soc. Neurochem. 12: 309a. 